\title{
43. Jahrestagung der Gesellschaft für Informatik
}

Vom 16. bis 20. September 2013 findet die 43. Jahrestagung der Gesellschaft für Informatik (GI) in Koblenz statt. Am Campus der Universität in Koblenz werden Workshops, Tutorien, wissenschaftliche und praxisnahe Sitzungen sowie sechs Partnerkonferenzen durchgeführt. Führende Personen aus Wissenschaft, Politik und Praxis geben einen Überblick über aktuelle Entwicklungen rund um das Leitthema der Tagung sowie über weitere aktuelle Ergebnisse aus Forschung und Entwicklung.

Ein Teil der Veranstaltung wird der Tag der Informatik sein. Dieser findet am Mittwoch, 18. September 2013 mit folgenden Programmpunkten statt:

\section{Eröffnung}

- Oliver Günther, Präsident der Gesellschaft für Informatik

\section{Eingeladene Vorträge}

Die Veranstalter freuen sich, folgende eingeladenen Vorträge ankündigen zu dürfen:

- Uwe Franke, Daimler AG

- Stereo and the City

- Bernhard Nebel, Uni Freiburg

- Automatic Planning: Making Autonomous Behavior Possible

- Hermann-Josef Lamberti, vorm.Vorstand Deutsche Bank
- Human and Device Centric Computing - a new paradigm beyond IT

- Marc-Oliver Gewaltig, EPFL Lausanne

- The Human Brain Project: Chances and challenges for computer science

Abwechslung von den üblichen Konferenzbeiträgen verspricht die Science Slam. Dabei versuchen die Teilnehmer Ihr Informatik-Forschungsthema in 10 Minuten möglichst spannend $\mathrm{zu}$ übermitteln. Die Science Slam findet am 19. September statt.

Mehr über die Höhe der Teilnahmegebühren, die Inhalte der angebotenen Workshops, Tutorien und Keynotes sowie über Möglichkeiten zur Übernachtung vor Ort erfahren Sie unter: http://informatik2013.de. Hier können Sie sich außerdem direkt für die Teilnahme an der GI-Konferenz registrieren.

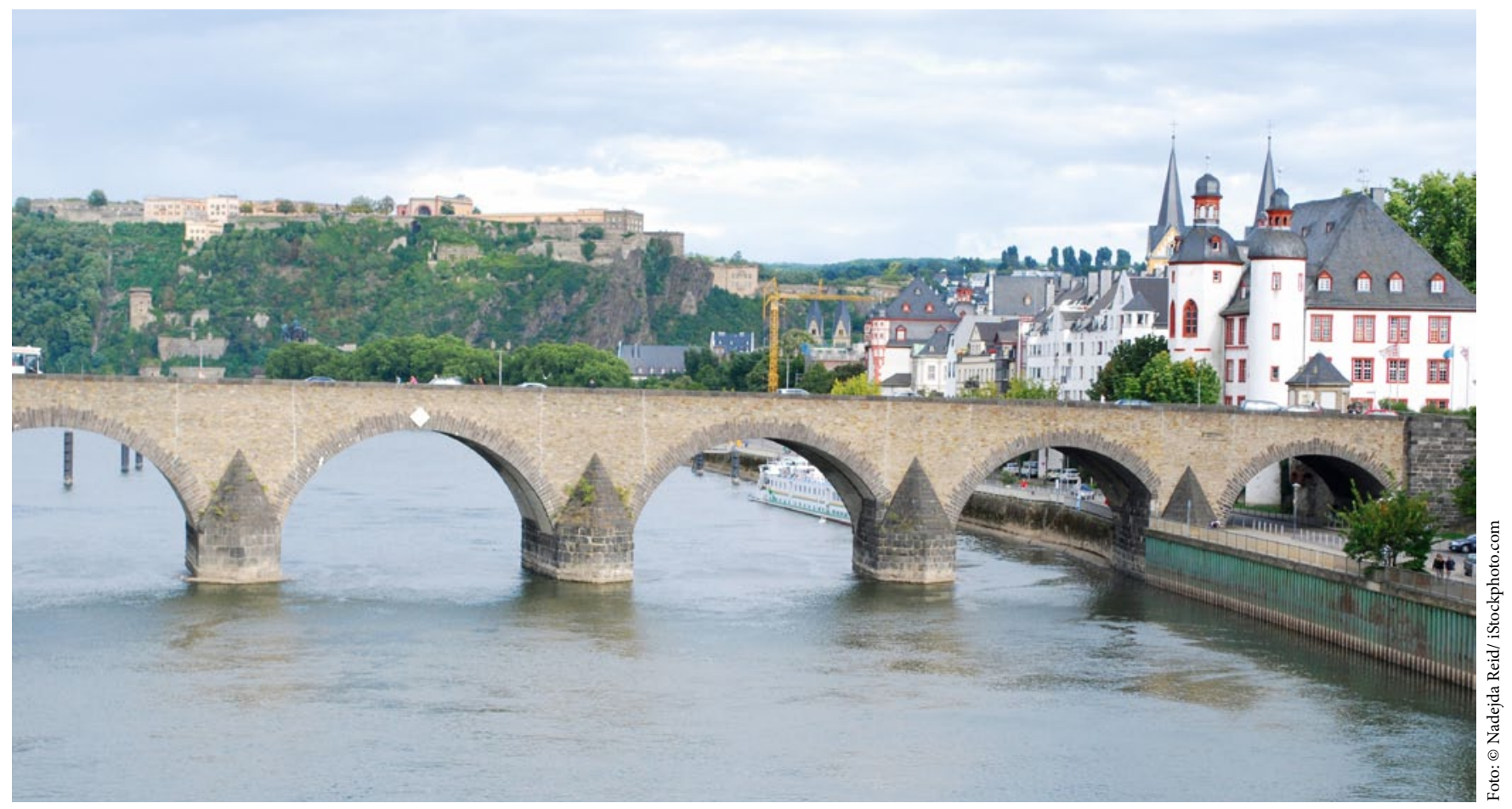

